\title{
Endoscopic repair of a colonic perforation following polypectomy using an endoclip
}

\author{
Sonny S Dhalla BSc MD FRCSC FACS
}

SS Dhalla. Endoscopic repair of a colonic perforation following polypectomy using an endoclip. Can J Gastroenterol 2004;18(2):105-106.

Endoscopic repair using an endoclip device for colonic perforation following polypectomy is described. This is the first case report of a repair following a regular polypectomy-induced perforation described in the English literature.

Key Words: Colonic perforation; Endoclip; Endoscopic repair; Post polypectomy

Dolypectomy using snare cautery is the standard treatment for most colonic polyps. This procedure is safe and well tolerated, with few complications. When perforation happens immediately, treatment is usually surgical repair or resection (1-4). The endoscopic clipping device is gaining widespread popularity in its use due to its ease of application (4). Marking lesions and control of bleeding are some of the accepted application of this device. The author describes a case of a patient who underwent repair of a colonic perforation following polypectomy using this endoscopic clipping device.

\section{CASE PRESENTATION}

A 78-year-old woman with multiple medical problems, consisting of severe osteoporosis, severe rheumatoid arthritis, early renal failure and congestive heart failure, presented with dyspnea. She had been on immunosuppressants, including steroids, and was found to be anemic with hemoglobin of $78 \mathrm{~g} / \mathrm{L}$. After being transfused and stabilized, she was prepped with an oral phosphate fleet solution at the referring hospital and was transferred to our regional hospital for colonoscopic evaluation. She was found to have an $8 \mathrm{~mm}$ polyp at the cecum. Polypectomy was carried out, but unfortunately the patient experienced immediate pain. It became apparent that the patient had suffered a perforation of colon, with an obvious pneumoperitoneum and distension of her abdomen along with protrusion of her umbilical hernia. Endoscopically, one could see the peritoneal contents. The defect measured at least 5 to $6 \mathrm{~mm}$. The cecal wall was noted to be thin. We decided to try this novel approach of an endoclip application to approximate the colonic defect in this high risk patient. Mucosa to mucosa approximation was achieved with placement of only two endoclips (Figure 1), using an HX-600-135 reloadable clip (Olympus America Inc, USA). Following the repair, colonic gas was suctioned. In addition, approximately $50 \mathrm{~mL}$ of

\section{La réparation endoscopique d'une perforation du côlon après une polypectomie au moyen d'une agrafe endoscopique}

Une réparation endoscopique effectuée au moyen d'une agrafe endoscopique afin de corriger une perforation du côlon est décrite. C'est le premier (deuxième) rapport de cas de réparation après une polypectomie régulière à être décrit dans la documentation scientifique de langue anglaise.

intravenous $\mathrm{x}$-ray contrast dye was placed at the repair site using an endoscopic retrograde cholangiopancreatography canula, to detect ongoing leakage by $\mathrm{x}$-ray. Because the patient was experiencing pain, most of the pneumoperitoneum was taken out with a 20-gauge intravenous catheter through the umbilicus. X-ray (Figure 2) and computed tomography scan (Figure 3 ) performed within the next $3 \mathrm{~h}$ showed no leak. The patient was placed on intravenous hydration and cefoxitin for $24 \mathrm{~h}$, followed by oral fluids and oral clavulin. She was

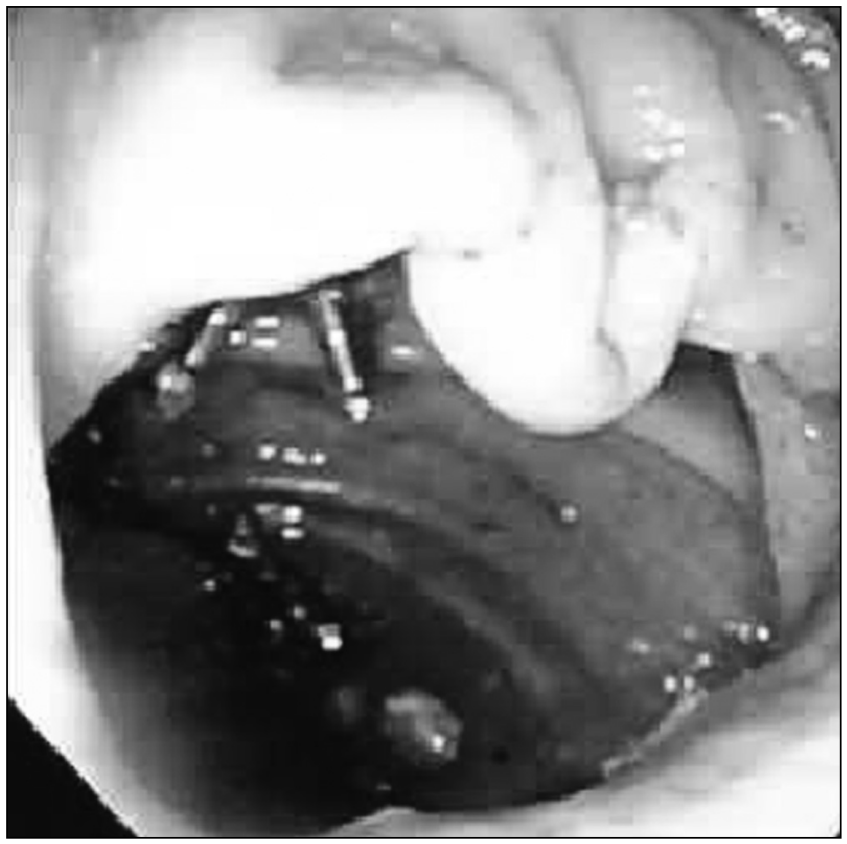

Figure 1) Repair of colonic perforation with placement of two endoclips

Brandon Regional Health Centre, Brandon, Manitoba

Correspondence and reprints: Dr Sonny S Dhalla, Varsity Medical, 335-18th Street, Brandon, Manitoba R7A 3N2. Telephone 204-728-9460, fax 204-728-9535,e-mail varsity@westman.wave.ca

Received for publication February 27, 2003. Accepted November 24, 2003 


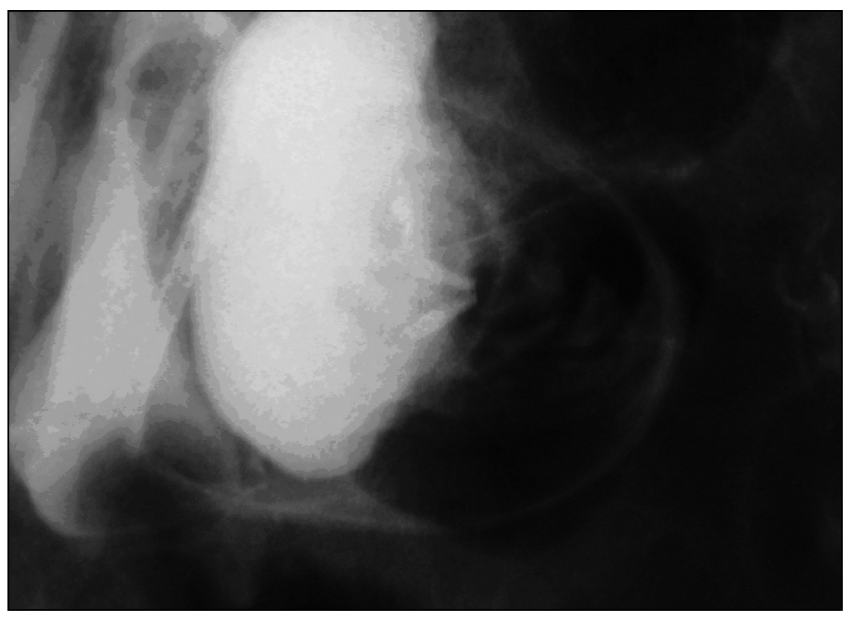

Figure 2) Abdominal x-ray showing no extravasation of contrast, following the procedure with endoclips

transferred back to her referring hospital for ongoing medical care two days postoperatively, and continued on oral clavulin for seven days, with complete resolution of symptoms. Follow-up phone calls at one week and at three months were uneventful.

\section{DISCUSSION}

Colonic perforations are rare in association with good colonscope technique (1-3). When diagnostic and therapeutic procedures such as large polypectomy and stricture dilatation result in long perforations, surgical repair or resection is usually advised. Conservative management may be preferable in selected cases where there is minimal fecal contamination (1-4). Broadspectrum antibiotics and intravenous hydration form the mainstay of this therapy.

Recent advances in endoscopic accessory devices has led to the introduction of novel approaches to correct certain problems encountered in the gastrointestinal tract (1-4). Ease in delivery and application of the recently introduced endoclip procedure is gaining popularity for the control of major gastrointestinal bleeding. The first report (1) described the application of five clips to an endoscopic mucosal resection site measuring approximately $15 \mathrm{~mm}$. The perforation was approximately $4 \mathrm{~mm}$. The patient had no pain at the time of perforation. However, this second case report in the English literature, using this novel approach to treat colonic perforation postpolypectomy, is described. The present case is

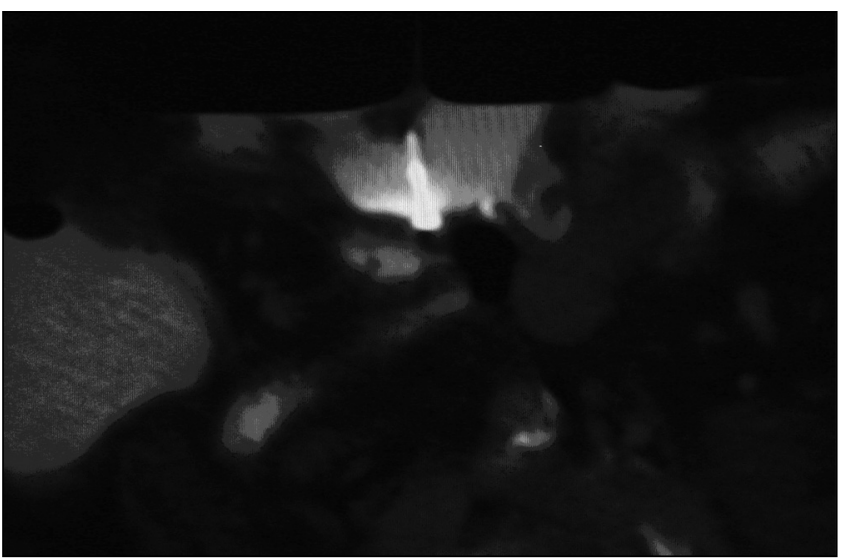

Figure 3) Computed tomography scan on bone window view, showing the endoclips with no leaking of the contrast

probably considered a normal scenario, with a standard polypectomy unfortunately resulting in a perforation. I believe that the endoclipping device should be considered (by an expert) before contemplating surgery. This technique is further simplified by the introduction of a new Olympus disposable clip, because no nursing time is necessary in preparing the device as in this case. I also suggest introducing $\mathrm{x}$-ray contrast dye to ensure no ongoing leak. A computed tomography scan performed after application of this procedure may also help in this conservative approach.

ACKNOWLEDGMENT: I would like to thank Dr Thomas Bevridge for his support in preparing this manuscript and Dr Gerry Couselan (Department of Radiology) for accommodating this patient expediently.

\section{REFERENCES}

1. Yoshikane H, Hidano H, Sakabara A, et al. Endoscopic repair by clipping of iatrogenic colonic perforation. Gastrointest Endosc 1997;46:464-6.

2. Mana F, DeVoglaere KD, Urban D. Iatrogenic perforation of the colon during diagnostic colonoscopy: Endoscopic treatment with clips. Gastrointest Endosc 2001;54:258-9.

3. Damore LJ, Ranitis PC, Vernava AM, et al. Colonoscopic perforation. Etiology, diagnosis and management. Dis Colon Rectum 1996;39:1306-14.

4. Binmoeller KF, Grimm H, Soehendra N. Endoscopic closure of a perforation using metallic clips after snare excision of a gastric leiomyoma. Gastrointest Endosc 1993;39:172-4. 


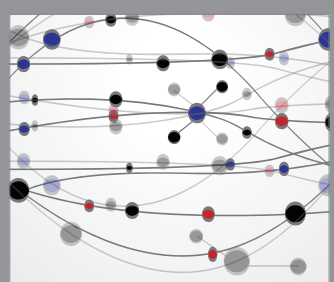

The Scientific World Journal
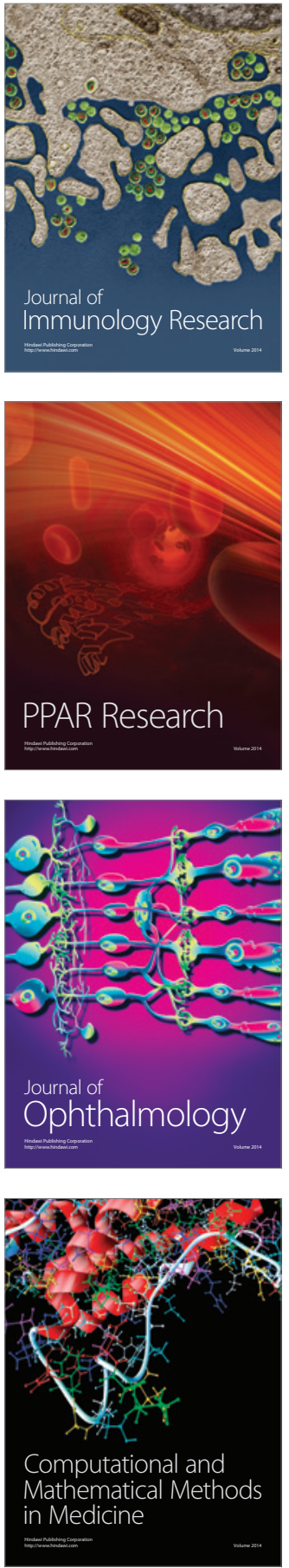

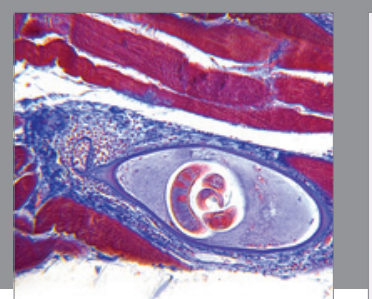

Gastroenterology Research and Practice

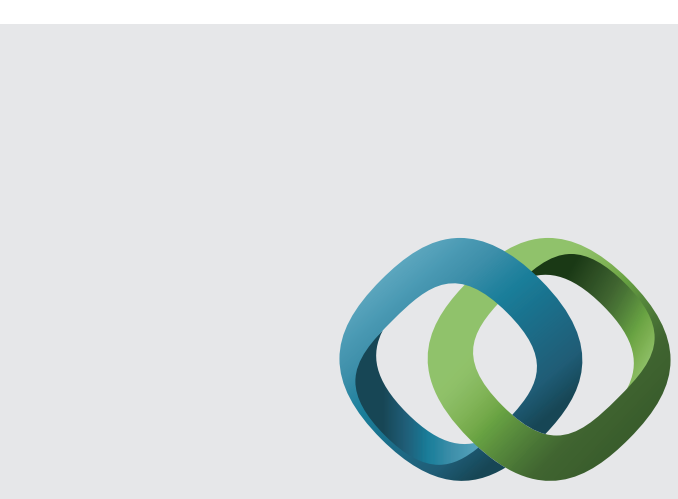

\section{Hindawi}

Submit your manuscripts at

http://www.hindawi.com
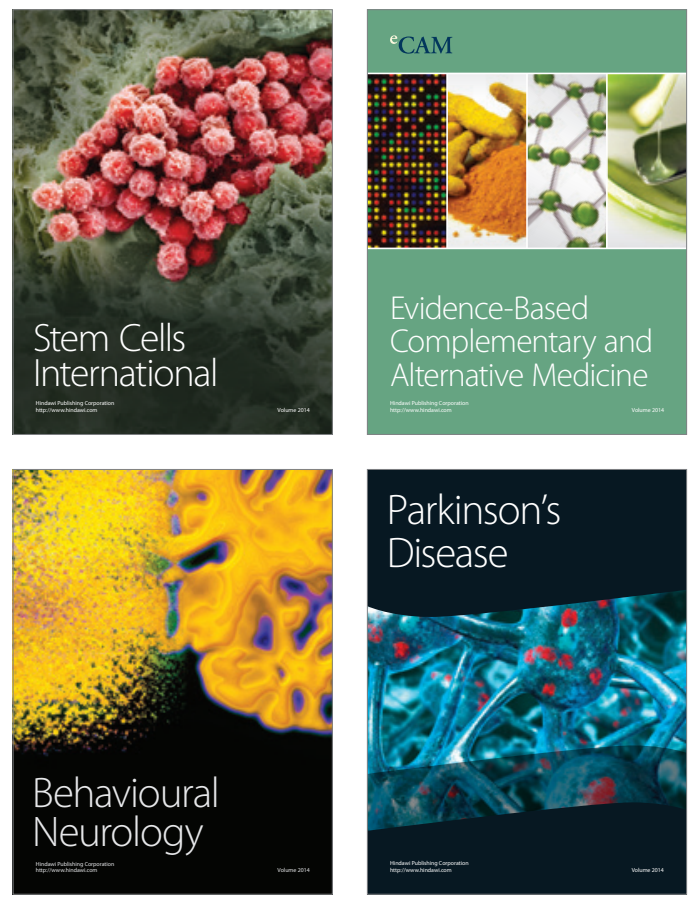
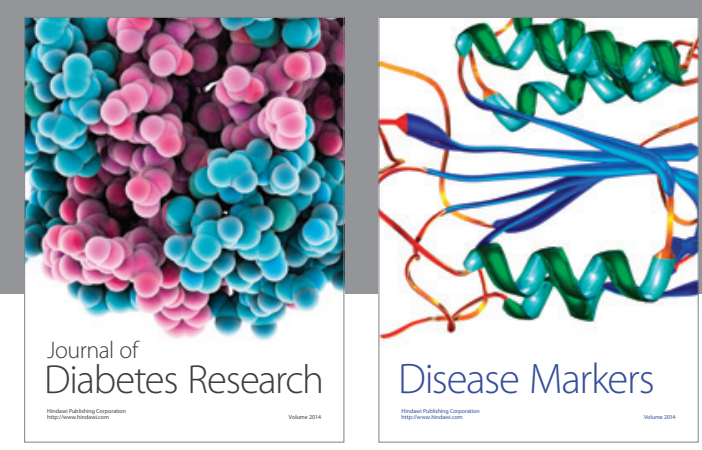

Disease Markers
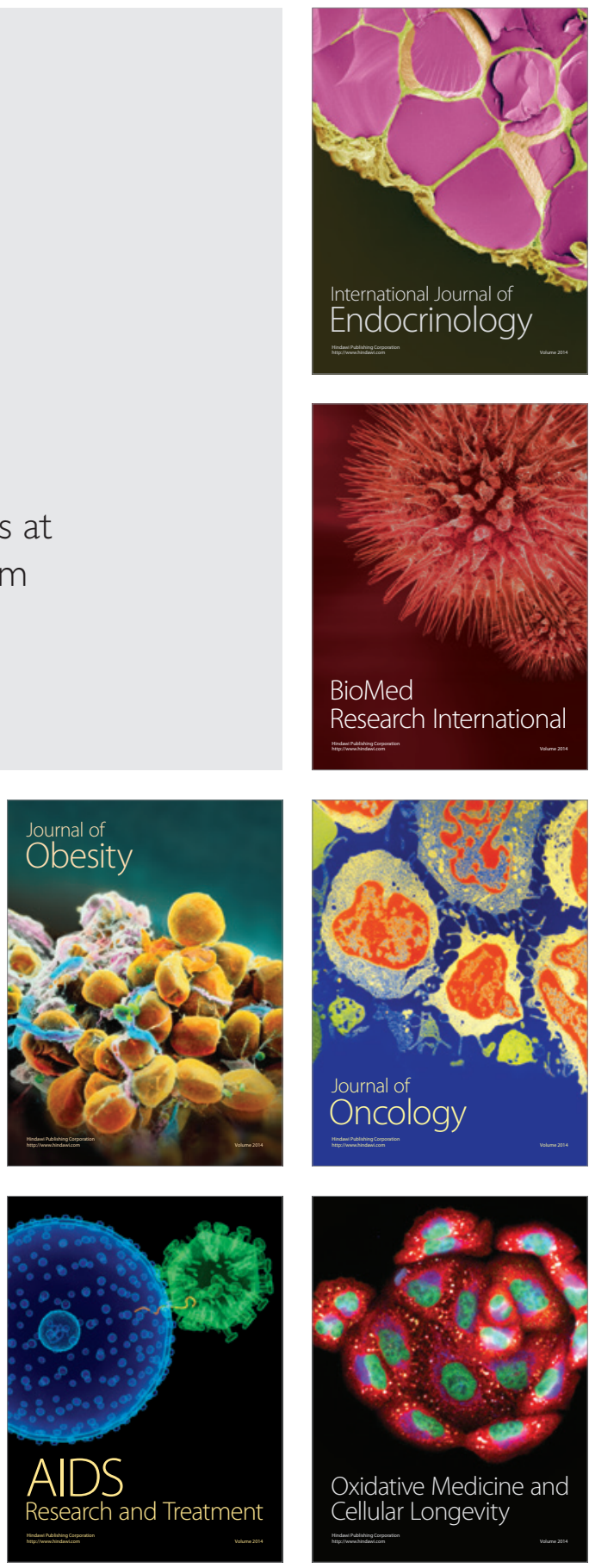